\title{
Four Secrets to Earning Patient Loyalty (Because three is not enough and five is far too many)
}

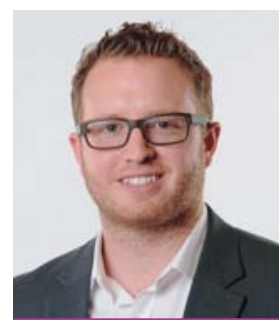

\section{Kevin Wilhelm, President of 4ECPs.}

4 ECPs is a business resource company for eye care professionals. Their divisions include a fullservice marketing agency, an online job board, an e-learning training website, payment processing and social media solutions. Visit www.4ecps.com to learn more about the company.

[Full disclosure: When I sat down to write this article, I first titled it Four Secrets to Winning Patient Loyalty. Before submitting, I realized I had created the wrong title. Winning, to me, implies a degree of luck. Yes, you can win a race but a true champion would rather say that they earned first place in the race. I knew I had to change the title to Earning Patient Loyalty because to do so requires strategy, commitment, hard work and dedication.]

\footnotetext{
A $\mathrm{s}$ the world continues to evolve into an increasingly digital age, eye care practices are struggling to adapt to $\triangle$ retain their patients. With the consolidated efforts of large chains and big box providers, the independent 1 - Loptometrist is left to compete against these giant retailers, many times without the tools required to make it a fair fight.
}

Patient acquisition is hard enough but getting a new patient in the door is only half the battle. Once they've become a patient, how do we keep them for life? How do we get them to tell their friends about us? How do we get them to spend more money with us? All of these questions should be considered when evaluating your overall patient experience at your practice.

Profitable growth in your practice can be sustained by earning patient loyalty. As alluded to above, earning loyalty is a long-term process which requires careful thought and complete buy-in from every member of your team. The vision starts at the top but needs to work it's way down to every stakeholder.

The following four steps outline key tactics that you can implement which will help you and your team earn loyalty from your patients, both in the short and long term.

\section{SAVE THEM TIME}

When your patients come into your office, do you know how much time they've allocated for their appointment? If you guessed 60 minutes, you would be correct. Typically, most people believe a medical appointment will take one hour. One way to lose patient loyalty is to keep your patients longer than the hour. Every minute past an hour it takes for your patients to stay in your office, the more frustrated they become. Every minute you save them, the more appreciative they will be.

Invest time and energy into your eye exam work flow. Think about all areas that can be organized more efficiently and ways to save your patients time and you'll start to shave off minutes here and there. Those precious minutes will not only increase the overall satisfaction of your patients visiting but you will also find that you can serve more patients each day and each patient will now have more time to spend in your dispensary, ultimately increasing the average patient value of your practice. 


\section{SAVE THEM HASSLE}

There is a perception that online shopping reduces the level of stress and hassle shoppers face when purchasing their glasses. People believe that they are saving both time and money while enjoying a more convenient experience. If this is the perception, what can your practice implement to switch this narrative? Look at every opportunity to reduce the pain points of your patients and customers when they visit for an eye exam or come in to purchase a pair of glasses.

Specifically, what are some things that you can change right now to reduce the hassle that your patients potentially face? Confirmations and reminders on booked appointments is a good start. Comfortable wait rooms with activities for children is another. Make your patients want to visit your dispensary before, during and after their appointment by creating a desirable retail experience. For patients who have purchased new glasses, create incredible warranties and guarantees on your products - reduce their risk and hassle on buying faulty frames. Follow up with past patients just to check in (especially if you've given them an updated RX) - see how they're doing. Lastly, implementing direct billing for insurance claims is another great way to reduce patient hassle.

\section{SHOW THEM SOMETHING NEW}

Do you remember the adage we learn something new every day? Visiting an Optometrist is a great place to learn something amazing about one of the most useful organs in the human body - the eye. Explain to your patients about the types of exams they'll be going through and what specifically you are looking for. Show them the images and test results and really explain the overall health of their eyes. Capitalize on this great opportunity to teach them something they wouldn't know about their eyes and how they work - especially children. The more you can teach, the more appreciation your patients will have for the work that you do.

When your patients finish their exams and head into your dispensary, this is another great opportunity to show them new lines of frames or technology that exist in eye wear. Show them your exclusive brands or your most popular lines. Have your Opticians walk them through certain frames that they feel would look great on them or suit their lifestyle. People generally want to be shown new and exciting things and will give you their time if they feel it will benefit them.

\section{DELIBERATELY EXCEED EXPECTATIONS}

This is a fun one. Deliberately exceeding expectations is where you and your staff can design fun and creative ways to show both value and personality to your patients. To find effective ways to accomplish this, the first step is to write down the typical patient experience at another optometrist's practice. List all points of contact the patient will have. For example: practice website, phone call, hold music, voicemail message, exterior signage, interior entrance, music playing, reception greeting, waiting room décor, fragrance and aroma, etc. are all points of contact that your patients will have with your practice.

Once your list is created including all points of contact, brainstorm ways that you can enhance your patient experience at each point. Ask your team questions like: How can we use the voicemail message to exceed expectations? How can we choose music that will exceed expectations? Some of these ideas may be completely out of the box while others might include a small tweak to what is already working. If you invest the time and energy into deliberately finding ways to exceed expectations, you'll accomplish this goal in no time. Loyalty is built when businesses go above what they're supposed to do and provide a level of service that is unexpected.

Now that you're ready to implement these four steps to earn patient loyalty, the key is to be consistent. Consistency breeds excellence and consistent excellence is required to build a strong brand. Think of ways to be remarkable every day and find a way to implement it with every patient, at every point of contact.

Earning patient loyalty is a long-term process - it doesn't just happen overnight. It requires strategy, dedication, focus and a willingness to invest time and energy. Once you achieve high loyalty, the payoffs are well worth the effort. Just take it a step at a time. 